\title{
Low saturated fat diet is effective in trigeminal neuralgia*
}

\author{
Narayan Verma ${ }^{1}$, Frank Sherwood ${ }^{2}$ \\ ${ }^{1}$ OUWB School of Medicine, Warren, USA; narayangod@aol.com \\ ${ }^{2}$ BG Tricounty Neurology and Sleep Clinic, Warren, USA
}

Received 13 June 2013; revised 15 July 2013; accepted 1 August 2013

Copyright (c) 2013 Narayan Verma, Frank Sherwood. This is an open access article distributed under the Creative Commons Attribution License, which permits unrestricted use, distribution, and reproduction in any medium, provided the original work is properly cited.

\begin{abstract}
Objective: To determine the effectiveness of low saturated fat diet (LSFD) in patients with trigeminal neuralgia (TN). Design: 1) Internet forum where patients could request a $\mathbf{1 0}$ page LSFD plan, and 2) Follow-up assessment done by a retrospective 20-item questionnaire. Duration of treatment -2 months to 13 years. Pain rated on a Visual Analogue Scale and reported as typical, atypical, or both, defining typical TN as intermittent quick jolts/stabbing pain and atypical TN as continuous never ending discomfort. Setting: General community. Patients: 55 unselected patients, most with unilateral, severe and daily symptoms in V2 and V3 distribution for a mean duration of 8 years and on medications. $84 \%$ had pain level 9 - 10 before treatment, 89\% had daily attacks and $31 \%$ had undergone surgical procedures. Intervention: LSFD for 2 months-13 years (mean 20 months). Main outcome measure: VAS score and medication use before and after LSFD treatment. Results: Reported SF content was 3 - $25 \mathrm{gm}$. With treatment $96 \%$ typical TN (p $<0.0001)$ and $71 \%$ atypical TN $(p<0.002)$ improved to level $0 \%-2.9 \%$ improved in less than a week, $47 \%$ in $1-2$ weeks and $44 \%$ in $3-4$ weeks. $66 \%$ rated their compliance with diet as excellent and $27 \%$ as good. There were no side effects except weight loss. $72 \%$ of those on medications reduced or discontinued them. All patients with post-surgical residual severe typical TN also improved $(p<0.0001)$. Conclusions: LSFD is effective in TN with high compliance, few adverse effects and may result in reduction/ elimination of medications even in most severe cases.
\end{abstract}

"Presented as a poster at AAN conference, New Orleans, April 24, 2012.
Keywords: Trigeminal Neuralgia; Low Saturated

Fat Diet; Cranial Neuropathy; Neuralgia

\section{INTRODUCTION}

Dietary treatment in neurological illnesses is not a novelty. The ketogenic diet for intractable childhood seizures is well known [1]. Efficacy of a dietary regimen in stabilizing the neuronal/axonal membranes in epileptics, presumed instability of membranes in the pathogenesis of trigeminal neuralgia (TN) and consequent efficacy of anticonvulsants in TN provides a therapeutic rationale for pursuing a dietary intervention in TN as well.

Late Roy L. Swank (1909-2008) introduced his low saturated fat diet (LSFD) in multiple sclerosis (MS) in 1948 and published data on 144 patients over a 34 year period in Lancet (1990) [2] regarding its effectiveness, and published again as a review in 2003 [3]. Although, not universally accepted, his results do provide a rationale to try LSFD in TN, as two percent patients with TN have MS [4].

$\mathrm{TN}$ is multi-factorial in etiology. Although vast majority are idiopathic, possible symptomatic etiologies include aneurysms, tumors, chronic meningeal inflammation, or other lesions such as abnormal vascular course of the superior cerebellar artery, primitive trigeminal artery, venous compression, an area of demyelination from multiple sclerosis or lesions in the pons at the root entry zone (REZ) of the trigeminal fibers, symptomatic intracranial hypotension, among others [5-8].

According to Weigel [9], no studies have ever tested the efficacy of diet in TN. This study aims to fulfill that vacuum.

\section{SUBJECTS AND METHODS}

One of us (FS) established an internet forum where patients with known TN could request a 10 page multicolored LSFD plan. He was motivated by improvement 
in his own serious health issues by this diet and a serendipitous improvement in the symptoms of a friend of his with severe TN for 21 years who was scheduled to undergo micro-vascular decompression, but was able to avoid that as she dramatically improved on this diet and remains so after 13 years.

The TN was diagnosed and treated by a board-certified neurologist or neurosurgeon in each case and their clinical characteristics are listed in results below. There were no exclusion criteria.

Patients rated their pain using the zero to 10 Visual Analogue Scale (VAS). They were instructed to report pain as typical, atypical, or both. Typical TN was defined as intermittent attacks of quick jolts of electrical-like stabbing excruciating pain and atypical TN as continuous never ending discomfort.

The plan had the diet instructions, the saturated fat (SF) content in 140 foods, recipes, how to read nutrition labels, suggestions for restaurant eating and related health information. Highlights of the diet are summarized in Table 1. The goal was to keep the daily saturated fat intake to as close to 10 gram as possible. The diet did not need to be plant based and animal products were not prohibited. Supplements, yoga, sunshine, lifestyle changes, exercise and smoking cessation were not required. Alcohol, salt, sugar, simple sugar products and caffeine were not restricted.

The follow-up assessment was done using a 20-item questionnaire administered retrospectively by e-mail.

The questionnaire requested the demographic information. Clinical status pre- and post-diet was ascertained as well.

Patient self-rated their compliance as excellent, good or poor.

Statistical analyses were done using the 2 tailed paired student's t test comparing the VAS scores before and after the dietary treatment.

Post-surgical subgroup was analyzed both as a part of the entire group as well as separately.

The questionnaires, the diet plans and mailings were all self funded.

A control group was not neither felt to be necessary or practical as patient's pre-diet status served as control.

Collateral benefits were qualitatively asked to be commented upon in an open ended question.

\section{RESULTS}

Table 2 illustrates the demographics and clinical characteristics of 55 unselected patients who returned the questionnaire. Vast majority had unilateral, severe and daily symptoms in V2 and V3 distribution for a mean duration of 8 years and were on medications. Eight patients (15\%) were not on any medication. The pain level was 9 - 10 in 75 percent of patients not on medications
Table 1. LSFD highlights.

\begin{tabular}{|c|c|}
\hline \multicolumn{2}{|c|}{ Foods that must be avoided } \\
\hline Lard & Butter \\
\hline Cream & Bacon \\
\hline Full fat Ice cream & Cheese \\
\hline All pastry & Nuts \\
\hline Coconut & Avocado \\
\hline Full fat yogurt & Margarine \\
\hline Soft candy & Pizza \\
\hline Gravies & Sauces \\
\hline \multicolumn{2}{|c|}{$\begin{array}{l}\text { Foods in moderation } \\
31 / 2 \text { ounces (The size of a deck of playing cards) }\end{array}$} \\
\hline \multicolumn{2}{|l|}{ Liver } \\
\hline \multicolumn{2}{|l|}{ Round } \\
\hline \multicolumn{2}{|l|}{ Lamb leg } \\
\hline \multicolumn{2}{|l|}{ Pork tenderloin } \\
\hline \multicolumn{2}{|l|}{ Cured ham } \\
\hline \multicolumn{2}{|l|}{ Ham steak } \\
\hline \multicolumn{2}{|l|}{ Eggs } \\
\hline \multicolumn{2}{|c|}{ Zero to very little saturated fat } \\
\hline Poultry (no skin) & Fish \\
\hline Canadian bacon & Veal \\
\hline Fat free luncheon meat & Soy cheese \\
\hline Spaghetti & Beans \\
\hline Low fat salad dressing & Rice \\
\hline Fat free dairy products & Canola oil \\
\hline Corn flakes & Oatmeal \\
\hline Pancakes & Bagels \\
\hline Cream of wheat & Bread \\
\hline Chestnuts & Olives \\
\hline Angle food cake & Pretzels \\
\hline Fat free ice cream & Hard candy \\
\hline Fat free puddings & Gelatin deserts \\
\hline \multicolumn{2}{|c|}{ Trigger foods } \\
\hline Tomatoes & Pickles \\
\hline Citrus fruits & Tea \\
\hline Coffee & Sugar \\
\hline Artificial sweeteners & Spices \\
\hline Hot sauce & Salt \\
\hline Pepper & Сосоа \\
\hline
\end{tabular}

and 85 percent of those on medications. Forty seven patients (85\%) were on medications: 19 on carbamazepine, 15 on gabapentin, 11 patients on oxcarbazepine, 6 patients on pregabalin, 4 patients on baclofen, 3 patients on topiramate, 3 patients on hydrocodone-acetaminophen, 2 patients on duloxetine, 2 patients on lamotrigine, 1 patient on phenytoin, 1 patient on amitriptyline, 1 on nortriptyline and one on acetaminophen-codeine.

Seventeen patients (31\%) had 35 surgical procedures with residual severe pain for a mean duration of 11 years: 5 microvascular decompressions, 7 glycerol injections, 7 
Table 2. Clinical characteristics of TN before treatment.

\begin{tabular}{|c|c|}
\hline \multicolumn{2}{|r|}{$\mathrm{N}=55$} \\
\hline Gender: & F 42, M 13 \\
\hline Age: & 28 - 89 (mean 58) \\
\hline Type: & typical 48, atypical 4, both 3 \\
\hline Laterality: & unilateral 46, bilateral 9 \\
\hline Branches affected: & $\begin{array}{l}\mathrm{V} 2 \text { and/or V3 in all except 2, V1 also } \\
\text { affected in addition to V2 and V3 in } 15\end{array}$ \\
\hline Duration: & 4 months-34 years (Mean 8 years) \\
\hline Co-existing MS: & yes 3 , no 52 \\
\hline Medications: & On meds 47 , not on meds 8 \\
\hline Intensity on VAS: & 9 - 10 (46), 7 - 8 (7), 5 - $6(2)$ \\
\hline \multicolumn{2}{|c|}{ Mean intensity on VAS for typical TN $(\mathrm{N}=51)=9.55 \pm 0.94^{*}$} \\
\hline \multicolumn{2}{|c|}{ Mean intensity on VAS for atypical TN $(\mathrm{N}=7)=8.57 \pm 1.13^{* *}$} \\
\hline Frequency: & daily 49 , weekly 6 , monthly 0 \\
\hline Surgery: & yes 17 (total 35 procedures), no 38 \\
\hline Occupation: & Various (see text) \\
\hline
\end{tabular}

*, ** These 2 lines add to 58 as 3 patients had both typical and atypical TN.

gamma knife surgeries, 12 radiofrequency ablation, 2 cyber knife surgeries, 1 balloon compression, and 1 surgery for neuralgia induced cavitational osteo-necrosis.

The following occupations were reported: college graduates, teachers, nurses, business owners, $\mathrm{PhD}$ candidate, senior vice president of finance, certified nutritionist, director of health services, physical therapist, hospital director of quality and risk management, credentialing, deputy prothontary, acupuncturist, defense contractor technician, geologist, NASA employee, university administrator, print shop coordinator, business consultant, para-optometrist, office manager, CPA, IT consultant, realtor, lifestyle counselor, computer operator, computer programmer, pastor, cosmetologist, secretary, salesmen, seamstress, domestic, homemaker and farmer.

\section{Post-Diet}

Table 3 shows results after LSFD treatment. Ninety six percent typical TN and 71 percent atypical TN improved to a pain level of 0 - 2 after 4 weeks of treatment.

Thirty four (72\%) of those on medications (47/55) reduced or discontinued them. Those who continued medications did so because either they were frightened or wanted to increase the percentage of LSFD to a tolerable level. Compliance was excellent or good in 93 percent.

Table 4 outlines the results in post surgical patients as a subgroup. All patients with post-surgical residual typical TN responded to LSFD except one patient whose typical TN improved but not the atypical TN. The speed of improvement was slightly longer (mean 20 days) than that for the entire group (mean 16 days). However, the mean duration of pain in the post surgical group was also longer (11 years vs. 8 years).
Table 3. Results with LSFD.

\begin{tabular}{|c|c|}
\hline $\begin{array}{l}\text { Reported daily } \\
\text { saturated fat intake: }\end{array}$ & 3 - 25 gm (mean 10 gm) \\
\hline \multirow[t]{2}{*}{ Duration: } & 2 months- 13 years (mean 20 months) \\
\hline & Excellent: 36 \\
\hline \multirow{2}{*}{ Compliance: } & good: 15 \\
\hline & poor: 4 \\
\hline Noticeable pain relief: & 1 week 26,2 weeks 25,3 - 4 weeks 4 \\
\hline Maximum pain relief: & $\begin{array}{l}1 \text { week } 5 \text {, } 2 \text { weeks } 27,3 \text { - } 4 \text { weeks } 23 \\
\text { (mean } 16 \text { days) }\end{array}$ \\
\hline \multirow{2}{*}{ Intensity on VAS: } & $0.14 \pm 1.45 \quad$ typical $\mathrm{TN}^{*}(0-249 / 51)$ \\
\hline & $2.28 \pm 2.92 \quad$ atypical $\mathrm{TN}^{* *}(0-25 / 7)$ \\
\hline Discontinued meds: & $16 / 47^{\#}$ \\
\hline Reduced meds: & $18 / 47^{\# \#}$ \\
\hline
\end{tabular}

Table 4. Post surgical patients.

\begin{tabular}{|c|c|}
\hline \multicolumn{2}{|r|}{$\mathrm{N}=17$} \\
\hline Procedures: & 35 (see text) \\
\hline Type: & typical TN 16, both 1 \\
\hline Laterality: & unilateral 14, bilateral 3 \\
\hline Duration: & 2 - 34 years (mean 11 years) \\
\hline Frequency: & daily 16 , weekly 1 , monthly 0 \\
\hline $\begin{array}{l}\text { Reported daily } \\
\text { saturated fat intake: }\end{array}$ & 3 - 16 gm (mean 11 gm) \\
\hline Compliance: & $\begin{array}{l}\text { Excellent: } 10 \\
\text { good: } 5 \\
\text { poor: } 2\end{array}$ \\
\hline Noticeable pain relief: & 1 week 10,2 weeks 6,3 - 4 weeks 1 \\
\hline Maximum pain relief: & $\begin{array}{l}1 \text { week } 1 \text {, } 2 \text { weeks } 8,3 \text { - } 4 \text { weeks } 8 \\
\text { (mean } 20 \text { days) }\end{array}$ \\
\hline Intensity of typical & Pre-diet: 6 - 10 (mean $9.53 \pm 1.07)$ \\
\hline TN on VAS: & 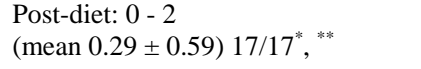 \\
\hline & Pre-diet: On meds 15 , not on meds 2 \\
\hline Medications: & $\begin{array}{l}\text { Post-diet: Discontinued meds } 4 \text {, } \\
\text { reduced } 9 \text {, continued } 2\end{array}$ \\
\hline
\end{tabular}

" paired 2 tailed student's $t$ test $t=31.7$ SED $=0.291, \mathrm{df}=16 \mathrm{p}<0.0001$ ${ }^{* *}$ One patient had atypical TN as well, with intensity of 8 , which did not change at all post-diet.

The data storm diagrams (Figures 1(a)-(c)) show that the VAS scores in typical TN, atypical TN and post-surgical patients respectively have virtually no overlap in the data before and after diet accounting for the statistically significant results.

Only side effect reported was weight loss. The amount of weight loss varied from 5 lbs to 75 lbs.

Collateral benefits qualitatively reported were lowered cholesterol levels and triglyceride levels, improved blood pressure, improvement of long standing itching, im- 


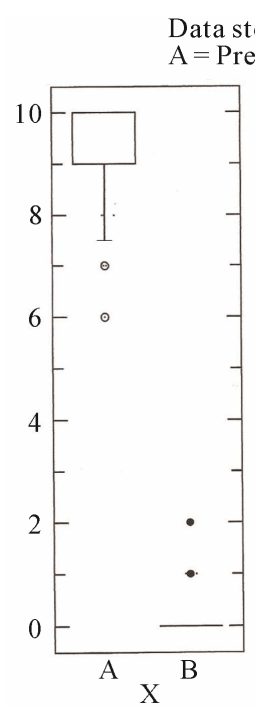

(a)
Data storm diagram of the VAS score $=$ Pre-diet

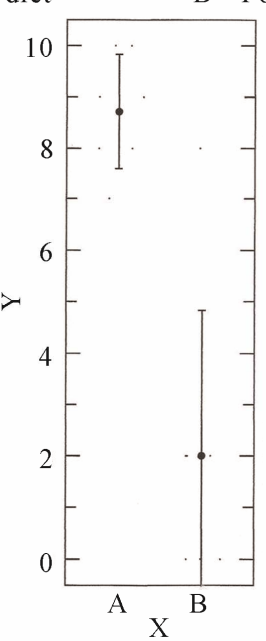

(b)

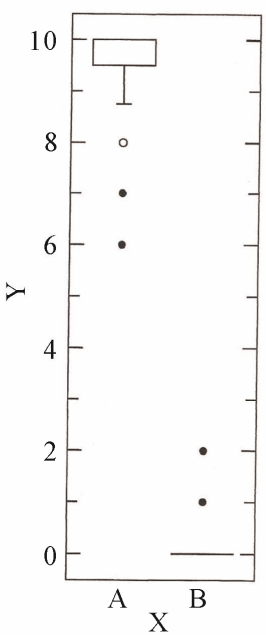

(c)
Figure 1. Data storm diagram comparing the VAS score before and after LSFD diet in each of the 3 groups: Typical TN, atypical TN and post-surgical TN showing hardly any overlap. (a) Typical TN (N = 51); (b) Atypical TN ( $=7)$; (c) Postsurgical subgroup $(\mathrm{N}=17)$.

proved GERD, reduction in wart size on hands, more energy level, more endurance and improved fibromylagic symptoms, constipation, hemorrhoids, migraines, sleep and Irritable bowel symptoms. One patient reported improved symptoms of glossopharyngeal neuralgia and another showed improvement in post-herpetic neuralgia which co-existed with TN.

\section{DISCUSSION}

LSFD for TN differs from other low saturated fat diets such as Ornish's [10] and Esselstyn's [11]. The Ornish diet is restrictive for patients because it limits alcohol, salt, oils, sugar, simple sugar derivatives, and does not allow caffeine. Ornish diet allows fish supplements and occasional consumption of animal products. Also for maximum results, the Ornish diet is to be used in conjunction with a holistic health program including, exercise, yoga, meditation, lifestyle changes, stress reduction, nutritional supplementation and smoking cessation. LSFD diet does not impose any such restrictions. Esselstyn diet is mostly plant-based vegan diet, which is hard to follow. LSFD does not require TN patients to be vegan. It simply strives to limit saturated fats to about 10 grams a day. Perhaps that is why the compliance was good to excellent in 93 percent. It cannot be compared to Mediterranean diet [12] as the latter has much higher saturated fat content-up to 8 percent and relies on the beneficial effects of wine, healthy lifestyle and sunlight as well.

Our results demonstrate that LSFD is a quick, safe and reliable method to treat both typical and atypical TN.
Ninety six percent typical TN and 71 percent atypical TN improved from a severe pain level to minimal $(0-2)$ in 1 - 4 weeks (average 2 weeks). Seventy two percent of patients on medications reduced or discontinued them. Typical TN in all surgical failures improved as well. Weight loss was the only side effect.

Women were overrepresented in our population, perhaps as they are more likely to surf the net for diets. Bilaterality was slightly more (16\%) than in the literature (12\%) and MS was more frequent (5.5\%) than in the literature (2\%) likely related to overrepresentation of women in the sample. Women are more likely to have MS and MS is the most common (18\%) known cause of bilateral trigeminal neuralgia [13,14]. Aside from this, the demographics and clinical features of our patients are in line with the literature indicating that even though they were not consecutive patients-impossible to obtain the low cost and novel method employed-they truly represent most TN patients. Given their background, it is likely that they answered the questionnaire honestly and accurately.

Some of the proposed mechanisms of TN [15-17] are as follows:

1) Neuropathic pain may be due to the small unmyelinated and thinly myelinated primary afferent fibers that sub serve nociception. 2) The pain mechanisms themselves may be altered. 3) Microanatomic small and large fiber damage in the nerve, essentially demyelination, commonly observed at the REZ, leads to ephaptic transmission, in which action potentials jump from one fiber to another. 4) A lack of inhibitory inputs from large myelinated nerve fibers may play a role. 5) A reentry mechanism may cause an amplification of sensory inputs such as from vibration, to trigger an attack. 6) Features also suggest an additional central mechanism (e.g., delay between stimulation and pain, refractory period).

LSFD is known to improve endothelial dysfunction and reduce inflammation by increasing the number of LDL receptors on mononuclear cells, influencing type 1 plasminogen inhibitor and $\mathrm{V}$ W factor, decreasing $\mathrm{P}$ selectin plasma levels and improving vasomotor function [18-20]. An improvement of the endothelial dysfunction and reduction of inflammation may well improve one or more underlying mechanisms detailed above. Reduced blood viscosity and decreased aggregation of blood cells [3] noted almost immediately after starting LSFD may improve circulation and blood-nerve barrier.

Whether long-term reduction of cholesterol levels and weight loss is operative in the improvement of $\mathrm{TN}$ is debatable as improvement occurred too soon for reduced cholesterol and weight loss to be a decisive factor. Relatively slow improvement in post-surgical group (mean of 20 days vs. 16 days) may well be related to longer duration of pain in that group (11 vs. 8 years) prior to treatment. 
The shortcomings of our study are that the data are self-reported from patients who are not directly under our care and the retrospective nature of the questionnaire. However, the technique employed by us is novel, low cost and deserves a second look for collecting data in difficult situations such as this. The placebo effect is not excluded although dramatic and sustained improvement even in post-surgical group with severe and intractable pain makes it unlikely. Dramatic and quick results may raise the question of biological improbability of the results but they are presented here as many novel therapies are initially serendipitous, and appear dramatic and improbable. A well designed prospective study with inclusion of a control group is necessary to further buttress the results. We also do not suggest that this improvement is specific for TN and overall contributions of unintentional life style modifications, which may occur while using this diet regardless, is not excluded, although the rapidity of improvement makes this possibility unlikely.

\section{REFERENCES}

[1] Freeman, J.M., Kossoff, E.H. and Hartman, A.L. (2007) The ketogenic diet: One decade later. Pediatrics, 119, 535-543. doi:10.1542/peds.2006-2447

[2] Swank, R.L. and Dugan, B.B. (1990) Effect of low saturated fat diet in early and late cases of multiple sclerosis. Lancet, 336, 37-39. doi:10.1016/0140-6736(90)91533-G

[3] Swank, R.L. and Goodwin, J. (2003) Review of MS patient survival on a Swank low saturated fat diet. Nutrition, 19, 161-162. doi:10.1016/S0899-9007(02)00851-1

[4] Jensen, T.S., Rasmussen, P. and Reske-Nielsen, E. (1982) Association of trigeminal neuralgia with multiple sclerosis: Clinical and pathological features. Acta Neurologica Scandinavica, 65, 182-189. doi:10.1111/j.1600-0404.1982.tb03076.x

[5] Anderson, V.C., Berryhill, P.C., Sandquist, M.A., Ciaverella, D.P., Nesbit, G.M. and Burchiel, K.J. (2006) Highresolution three-dimensional magnetic resonance angiography and three-dimensional spoiled gradient-recalled imaging in the evaluation of neurovascular compression in patients with trigeminal neuralgia: A double-blind pilot study. Neurosurgery, 58, 666-673. doi:10.1227/01.NEU.0000197117.34888.DE

[6] Hess, B., Oberndorfer, S., Urbanits, S., Lahrmann, H., Horvath-Mechtler, B. and Grisold, W. (2005) Trigeminal neuralgia in two patients with glioblastoma. Headache, 45, 1267-1270. doi:10.1111/j.1526-4610.2005.00253_3.x

[7] Cheshire Jr., W.P. (2000) The shocking tooth about trigeminal neuralgia. The New England Journal of
Medicine, 342, 2003. doi:10.1056/NEJM200006293422619

[8] Cheshire Jr., W.P. and Wharen Jr., R.E. (2009) Trigeminal neuralgia in a patient with spontaneous intracranial hypotension. Headache, 49, 770-773. doi:10.1111/j.1526-4610.2009.01403.x

[9] Weigel, G. and Casey, K.E. (2004) Striking back! In: Weigel, G. and Casey, K.E., Eds., The Trigeminal Neuralgia and Face Pain Handbook, TNA, Gainsville, 346.

[10] Ornish, D., Scherwitz, L.W., Doody, R.S., Kesten, D., McLanahan, S.M., Brown, S.E., et al. (1983) Effects of stress management training and dietary changes in treating ischemic heart disease. JAMA, 249, 54-59. doi:10.1001/jama.1983.03330250034024

[11] Esselstyn Jr., C.B., Ellis, S.G., Medendorp, S.V. and Crowe, T.D. (1995) A strategy to arrest and reverse coronary artery disease: A 5-year longitudinal study of a single physician's practice. The Journal of Family Practice, 41, 560-588.

[12] Willett, W.C. (2006) The Mediterranean diet: science and practice. Public Health Nutrition, 1A, 105-110.

[13] Brisman, R. (1987) Bilateral trigeminal neuralgia. Journal of Neurosurgery, 67, 44-48. doi:10.3171/jns.1987.67.1.0044

[14] Brisman, R. (1987) Trigeminal neuralgia and multiple sclerosis. Archives of Neurology, 44, 379-381. doi:10.1001/archneur.1987.00520160021008

[15] Singh, M.K. and Egan, R.A. (2011) Trigeminal neuralgia. Medscape.

[16] Burchiel, K.J. (1980) Abnormal impulse generation in focally demyelinated trigeminal roots. Journal of Neurosurgery, 53, 674-683. doi:10.3171/jns.1980.53.5.0674

[17] Devor, M., Amir, R.and Rappaport, Z.H. (2002) Pathophysiology of trigeminal neuralgia: The ignition hypothesis. The Clinical Journal of Pain, 18, 4-13. doi:10.1097/00002508-200201000-00002

[18] Fuestes, F., Lopex-Miranda, J., Sanchez, E., et al. (2001) Mediterranean and low-fat diets improve endothelial function in hypercholesterolemic men. Annals of Internal Medicine, 134, 1115-1119. doi:10.7326/0003-4819-134-12-200106190-00011

[19] Mustad, V.A., Etherton, T.D., Cooper, A.D., et al. (1997) Reduced saturated fat intake in associated with increased levels of LDL receptors on mononuclear cells in healthy men and women. The Journal of Lipid Research, 39, 459-468.

[20] Riccio, P., Rossano, R. and Liuzzi, G.M. (2010) May diet and dietary supplements improve the wellness of multiple sclerosis patients? A molecular approach. Autoimmune Disease, 2010, Article ID: 249842. 